ISSN1027-5495. Functional Materials, 23, No.1 (2016), p. 138-145.

doi:http://dx.doi.org/10.15407/fm23.01.138

(C) 2016 - STC “Institute for Single Crystals"

\title{
Inflection moment calculation and resilience analysis of roller straightening
}

\author{
Jin Herong ${ }^{1,2}$, Lu Xiuchun ${ }^{3}$ \\ ${ }^{1}$ Key Laboratory of Advanced Forging \& Stamping Technology \\ and Science of Ministry of National Education, Yanshan University, \\ Qinhuangdao, Hebei, 066004, P.R. China \\ ${ }^{2}$ Parallel Robot and Mechatronic System Laboratory of Hebei Province, \\ Yanshan University, Qinhuangdao, Hebei, 066004, P.R. China \\ ${ }^{3}$ School of Mechanical Engineering, Yanshan University, \\ Qinhuangdao, 066004, China
}

\section{Received July, 25, 2015}

\begin{abstract}
Based on elastic-plasticity theory and appropriate mathematical model, stress and strain of steel bars in arbitrary bending state during the process of straightening is analyzed to deduce original ratio of curvature, the included angle between original bending plane and inflection plane and inflection moment. Corresponding resilience is analyzed to come to a conclusion that rebound plane turn around neutral axis to inflection plane. Roller system configuration of threeroller equal curvature of hot rolled ribbed steel bar is proposed to solve the problem that the steel bar rotate around its own axis during the straightening course, so comprehensive circle straightening is accomplished and straightening precision is improved.
\end{abstract}

Keywords: Roller straightening, equal curvature, three-roller standstill, resilience.

Основываясь на теории эластичности и пластичности и соответствующей математической модели, проанализированы нагрузки и напряжения стальных брусков в произвольном состоянии изгиба во время процесса выправления для определения исходного порядка кривизны, угла между исходной изгибающейплоскостью иплоскости изгибания, и изгибающего момента. Анализ соответствущих характеристик эластичности позволил сделать вывод, что возникающий поворот плоскости происходит вокруг нейтральной оси к плоскости изгибания. Конфигурация системы роликов с равной кривизной по отношению к трем роликам горячего ребристого стального бруска, как предполагается, может решить задачу вращения стального бруска вокруг своей оси в ходе выправления. Таким образом, осуществляется полный цикл выправления, вследствие чего точность выправления улучшается.

Розрахунок згинального моменту та аналіз еластичності при правленні обертових вальців. Цзінь Хежон, Лю Сючунь

Базуючись на теорії еластичності і пластичності та відповідній математичній моделі, проаналізовано навантаження та напруги сталевих брусків у довільному стані згину під час процесу правлення для визначення висхідного порядку кривизни, кута між висхідною згинальною площиною і площиною вигину, а також згинального моменту. Аналіз відповідних характеристик еластичності призвів до висновку, що результуючий поворот площини відбувається навколо нейтральної осі до площини вигину. Конфігурація системи вальців з кривизною, однаковою щодо трьох вальців гарачого ребристого сталевого бруска, як припускаеться, може вирішити задачу обертання сталевого бруска навколо своеї осі під час правлення. Таким чином, реалізується повний цикл правлення, внаслідок чого точність правлення підвищуеться. 


\section{Introduction}

Steel bars are used for pre-stressing concrete structural units such as beams and girders, and for the construction of suspension bridges among other application in civil engineering. Roller straightening machine with two-row staggered arrangement work rolls to eliminate the uneven curvature of curved bars after repeated bending and make the curvature diminish, so it has the advantage of small residual stress and stable flatness to be widely used in the straightening of steel, aluminum alloy and magnesium alloy[1-3]. But with the development of industry, especially the development of automatic straightening technology, the traditional method can't meet the requirement of straightening precision. The further research of elastic-plastic deformation to realize standstill locking of bar in straightening process, ensure straightening plane perpendicular, improve straightening precision, has become urgent problems for straightening technology [4-6].

The early works were focused on general analysis of the mechanics involved in the straightening process of bars and sections[7]. In recent years, many research achievements in the aspect of bar straightening have been obtained by researchers. Hamada Ryota, Asakawa Motoo et al. noticed that higher straightness was not able to achieved by roller leveler because of the tilting of bars during straightening. They investigated roller leveler mechanism by numerical and experimental analysis to estimate the limit value of straightness and bar tilting[8]. Kazeem K, Adewole conducted three-dimensional FE simulation of the reverse bending and straightening of steel bars over three rotating rollers and demonstrated that the bending simulation procedure employed was able to predict a maximum bending strain that agreed with an existing analytical expression[9]. J. S. Lee et al. performed the optimization of the roller straightening process for steel cords by the response surface method. The optimum design can reduce the residual stress of wire remarkably and make the bent wire straight[10]. LU Hong et al. proposed a novel way of predicting the straightening stroke based on mathematical methods and bending experimental and numerical simulation. The stroke prediction formula with high precision can be applied to the straightening stroke prediction in the high straightness metal bar manufacturing process and automatic straightening machine conveniently[11]. Wilhelm Guericke presented a material model, which described the elastic-plastic stress-strain course of cyclic tension-compression deformation with variable amplitudes[12]. The material model can be ap-

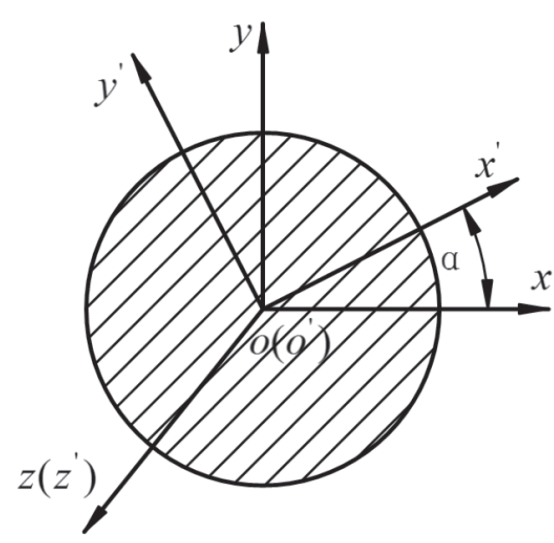

Fig. 1. The coordinate system on the cross-section

plied as a subsystem in a roller straightening process model and it has been successfully used in practice.

The original bending of bar may be any shape, may be at any surface. This article is concerned with the calculation of bending moment and rebound direction while original bending plane is at any angle to inflection plane. Under definite inflection ratio of curvature, the calculation formula of inflection bending moment is deduced while original bending plane is at any angle to inflection plane (straightening plane). The conclusion that bouncing plane tend toward inflection plane gradually is drawn, this provide theory basis for the any direction bending of bars in slab edge combination roll system.

\section{Stress strain and bouncing of any section of bar}

During the straightening of bars, for any infinitesimal section of steel bars, we assume the original curvature to be $A_{0}$, inflection curvature to be $A_{w}$. Choose a section perpendicular to neutral axis at any part of infinitesimal section and build coordinate system shown in Figure 1.

Assume original bending plane is $x^{\prime} o^{\prime} z^{\prime}$, inflection (straightening) plane is yoz(the straightening direction is along the negative of y-axis), the included angle between $x^{\prime} o^{\prime} z^{\prime}$ and $x o z$ plane is a, the included angle between original bending plane and inflection plane is Y. Any infinitesimal area of the section can be represented by $r d r d \theta$, shown in Figure 2. Due to the symmetry of circle section, the bending moment of half section only need to be calculated.

For the strain of any infinitesimal area, it can be calculated into two parts.

Strain of $x^{\prime} o^{\prime} z^{\prime}$ plane

$$
\varepsilon^{\prime}=A_{0} r \cos (\alpha-\theta)
$$




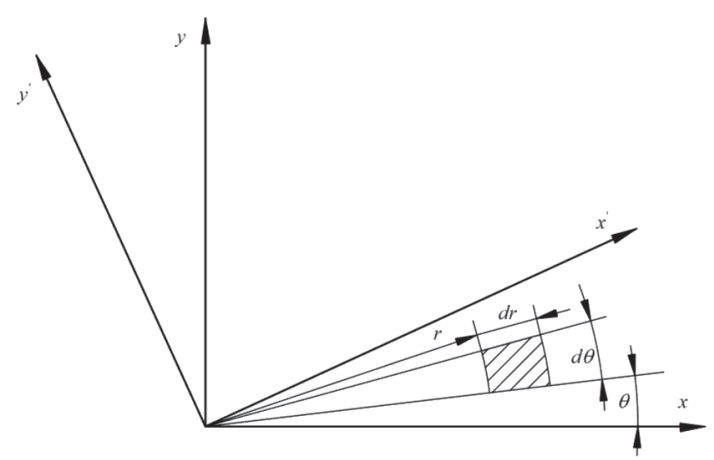

Fig. 2. Any infinitesimal area of the section

Strain of yoz plane

$$
\varepsilon^{\prime \prime}=A_{w} r \sin \theta
$$

where, $A_{0}$ is original curvature; $A_{w}$ is inflection curvature.

The whole strain is

$$
\varepsilon=\varepsilon^{\prime}+\varepsilon^{\prime \prime}=A_{0} r \cos (\alpha-\theta)+A_{w} r \sin \theta
$$

$=r\left[\left(A_{0} \sin \alpha+A_{w}\right) \sin \theta+\left(A_{0} \cos \alpha\right) \cos \theta\right]$

Let $\quad a=A_{0} \cos \alpha, \quad b=A_{0} \sin \alpha+A_{w}$, $c=\sqrt{a^{2}+b^{2}}, \tan A=a / b$, then the following formulae are obtained.

$\int\left(A_{0} \sin \alpha+A_{w}\right) \sin \theta+\left(A_{0} \cos \alpha\right) \cos \theta=c \cdot \sin (A+\theta)$ $\{\varepsilon=r c \sin (A+\theta)$

For perfect elastic-plastic material, when $\varepsilon \geq \varepsilon_{t} \quad(\varepsilon=r c \sin (A+\theta)), \sigma=\sigma_{t}$, accordingly

$$
\arcsin \left(\frac{\varepsilon_{t}}{c r}\right)-A \leq \theta \leq \pi-A-\arcsin \left(\frac{\varepsilon_{t}}{c r}\right)
$$

When $r=R$ ( $\mathrm{R}$ is radius of bar), the area of $\varepsilon \geq \varepsilon_{t}$ can be gained as follows

$$
\begin{gathered}
\arcsin \left(\frac{\varepsilon_{t}}{c R}\right)-A \leq \theta \leq \pi-A-\arcsin \left(\frac{\varepsilon_{t}}{c R}\right) \\
\frac{\varepsilon_{t}}{c \sin (A+\theta)} \leq r \leq R
\end{gathered}
$$

The force exerted on any infinitesimal area $(\operatorname{rdrd} \theta)$ is

$$
d F=E \cdot c \cdot r \cdot \sin (A+\theta) \cdot r d r d \theta
$$

The bending moment which is exerted on $\mathrm{x}$ axis by the force is

$$
d M=d F \cdot r \sin \theta=E c r^{3} \sin (A+\theta) \sin \theta d r d \theta
$$

During straightening, for any circular cross section $\mathrm{D}$, stress $\varepsilon(x, y)$ is continuous at the section. For any infinitesimal closed region $d A, \quad d A=r d r d \theta . \quad d F_{x}=y \sigma(x, y) d A \quad$ and $d F_{y}=x \sigma(x, y) d A$ denote the static moments this stress about $\mathrm{x}$-axis and $\mathrm{y}$-axis respectively. Take these elements as integrand expressions

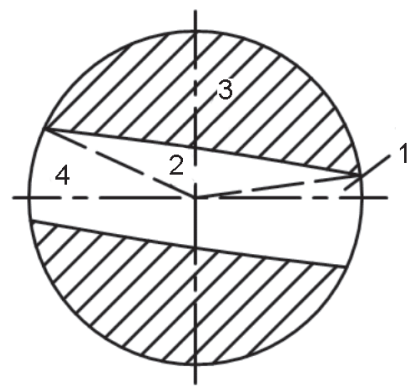

Fig. 3. The region map of the first type deformation

and perform integration at closed interval $\mathrm{D}$ to obtain static moment as

$$
\begin{aligned}
F_{x} & =\iint_{D} y \sigma(x, y) d A \\
F_{y} & =\iint_{D} x \sigma(x, y) d A
\end{aligned}
$$

The stress of this circular section is

$$
F=\iint_{D} \sigma(x, y) d A
$$

Then the center of circular section stress is denoted as

$$
\begin{aligned}
& \bar{x}=\frac{F_{y}}{F}=\frac{\iint_{D} x \sigma(x, y) d A}{\iint_{D} \sigma(x, y) d A} \\
& \bar{y}=\frac{F_{x}}{F}=\frac{\iint_{D} y \sigma(x, y) d A}{\iint_{D} \sigma(x, y) d A}
\end{aligned}
$$

The included acute angle between bouncing plane and inflection plane is denoted as $\beta$

$$
\beta=\arctan \left(\frac{\bar{x}}{y}\right)=\arctan \left(\frac{F_{y}}{F_{x}}\right)
$$

For upper half circular section, the calculation of bending moment and bouncing can be divided into the following two strained conditions.
(1) $\arcsin \left(\frac{\varepsilon_{t}}{c R}\right)-A \geq 0$
(2) $\arcsin \left(\frac{\varepsilon_{t}}{c R}\right)-A<0$

\section{Calculation of inflection moment and analysis of resilience under the first condition}

\subsection{Calculation of Inflection Moment}

Under the first condition, that is meet the condition of $\arcsin (\varepsilon t / c R)-A \geq 0$, plastic deformed area of upper half section does not in- 
tersect $\mathrm{x}$ axis and integral domain can be distributed into four parts, which is shown in Figure 3 , the dashed area represents the plastic deformed area.

The stress and bending moment correspond with upper half section can be expressed as the following four parts.

(1) Integral domain $D_{1}$

$$
\begin{aligned}
& 0 \leq \theta \leq \arcsin \left(\frac{\varepsilon_{t}}{c R}\right)-A \\
& 0 \leq r \leq R
\end{aligned}
$$

The stress correspond with this domain is

$$
\sigma_{1}=\operatorname{Ecr} \sin (A+\theta)
$$

The bending stress is

$$
\begin{aligned}
& M_{1}=\iint_{D_{1}} d M= \\
& =\int_{0}^{\arcsin \left(\frac{\varepsilon_{t}}{c R}\right)-A} \int_{0}^{R} E C \sin (A+\theta) r^{3} \sin \theta d r d \theta \\
& =E C \int_{0}^{\arcsin \left(\frac{\varepsilon_{t}}{c R}\right)-A} \sin (A+\theta) \sin \theta d \theta \int_{0}^{R} r^{3} d r
\end{aligned}
$$

(2) Integral domain $D_{2}$

$$
\begin{aligned}
& \arcsin \left(\frac{\varepsilon_{t}}{c R}\right)-A \leq \theta \leq \pi-A-\arcsin \left(\frac{\varepsilon_{t}}{c R}\right) \\
& 0 \leq r \leq \frac{\varepsilon_{t}}{c \sin (A+\theta)}
\end{aligned}
$$

The stress correspond with this domain is

$$
\sigma_{2}=\operatorname{Ecr} \sin (A+\theta)
$$

The bending stress is

$$
M_{2}=\iint_{D_{2}} d M=
$$

$=\int_{\arcsin \left(\frac{\varepsilon_{t}}{c R}\right)-A}^{\pi-A-\arcsin \left(\frac{\varepsilon_{t}}{c R}\right)} \int_{0}^{\frac{\varepsilon_{t}}{c \sin (A+\theta)}} E C \sin (A+\theta) r^{3} \sin \theta d r d \theta$ $=E C \int_{\arcsin \left(\frac{\varepsilon_{t}}{c R}\right)-A}^{\pi-A-\arcsin \left(\frac{\varepsilon_{t}}{c R}\right)} \sin (A+\theta) \sin \theta d \theta \int_{0}^{\frac{\varepsilon_{t}}{c \sin (A+\theta)}} r^{3} d r$

(3) Integral domain $D_{3}$ (the upper half dashed area)

$$
\begin{aligned}
& \arcsin \left(\frac{\varepsilon_{t}}{c R}\right)-A \leq \theta \leq \pi-A-\arcsin \left(\frac{\varepsilon_{t}}{c R}\right) \\
& \frac{\varepsilon_{t}}{c \sin (A+\theta)} \leq r \leq R
\end{aligned}
$$

The stress correspond with this domain is

$$
\sigma_{3}=\sigma_{t}
$$

The bending stress is

$$
\begin{aligned}
& M_{3}=\iint_{D_{3}} \sigma_{t} \sin \theta r^{2} d r d \theta= \\
& =\int_{\arcsin \left(\frac{\varepsilon_{t}}{c R}\right)-A}^{\pi-A-\arcsin \left(\frac{\varepsilon_{t}}{c R}\right)} \int_{\frac{\varepsilon_{t}}{c \sin (A+\theta)}}^{R} \sigma_{t} \sin \theta r^{2} d r d \theta \\
& =\int_{\arcsin \left(\frac{\varepsilon_{t}}{c R}\right)-A}^{\pi-A-\arcsin \left(\frac{\varepsilon_{t}}{c R}\right)} \sigma_{t} \sin \theta d \theta \int_{\frac{\varepsilon_{t}}{c \sin (A+\theta)}}^{R} r^{2} d r
\end{aligned}
$$

(4) Integral domain $D_{4}$

$$
\begin{aligned}
& \pi-A-\arcsin \left(\frac{\varepsilon_{t}}{c R}\right) \leq \theta \leq \pi \\
& 0 \leq r \leq R
\end{aligned}
$$

The stress correspond with this domain is

$$
\sigma_{4}=\operatorname{Ecr} \sin (A+\theta)
$$

The bending stress is

$$
\begin{aligned}
& M_{4}=\iint_{D_{4}} d M= \\
& =\int_{\pi-A-\arcsin \left(\frac{\varepsilon_{t}}{c R}\right)}^{\pi} \int_{0}^{R} E C \sin (A+\theta) r^{3} \sin \theta d r d \theta \\
& =E C \int_{\pi-A-\arcsin \left(\frac{\varepsilon_{t}}{c R}\right)}^{\pi} \sin (A+\theta) \sin \theta d \theta \int_{0}^{R} r^{3} d r
\end{aligned}
$$

Total bending moment of the circular section is

$$
\begin{aligned}
& M=2 \cdot \sum_{i=1}^{4} M_{i} \\
& =\frac{E c R^{4}}{2}\left\{\cos A \cdot \arcsin \left(\frac{\varepsilon_{t}}{c R}\right)-\cos A+\frac{\varepsilon_{t} \sqrt{(c R)^{2}-\varepsilon_{t}{ }^{2}}}{(c R)^{2}}\right\} \\
& =\frac{4 \sigma_{t} R^{2} c^{2}-\sigma_{t} \varepsilon_{t}{ }^{2}}{3 c^{3}} \cos A \sqrt{(c R)^{2}-\varepsilon_{t}{ }^{2}}
\end{aligned}
$$

\subsection{Analysis of Resilience}

Corresponding to the four integral domains divided by the upper half section under the status of $\arcsin \left(\varepsilon_{t} / c R\right)-A \geq 0, \quad F_{x}$ consists of the four parts

$$
\left\{\begin{array}{l}
F_{x 1}=\iint_{D_{1}} d F_{x} \\
F_{x 2}=\iint_{D_{2}} d F_{x} \\
F_{x 3}=\iint_{D_{3}} \sigma_{t} r^{2} \sin \theta d r d \theta \\
F_{x 4}=\iint_{D 4} d F_{x}
\end{array}\right.
$$

Where $d F_{x}$ is

$$
d F_{x}=E c r^{3} \sin (A+\theta) \sin \theta d r d \theta
$$




$$
\begin{aligned}
F_{x}= & \sum_{i=1}^{4} F_{x i} \\
= & \frac{E c R^{4}}{4}\left\{\cos A \arcsin \left(\frac{\varepsilon_{t}}{c R}\right)-\cos A \frac{\varepsilon_{t} \sqrt{(c R)^{2}-\varepsilon_{t}^{2}}}{(c R)^{2}}\right\}+ \\
& \frac{4 \sigma_{t} R^{2} c^{2}-\sigma_{t} \varepsilon_{t}{ }^{2}}{6 c^{3}} \cos A \sqrt{(c R)^{2}-\varepsilon_{t}^{2}}
\end{aligned}
$$

Corresponding $F_{y}$ consists of the four parts

$$
\left\{\begin{array}{l}
F_{y 1}=\iint_{D_{1}} d F_{y} \\
F_{y 2}=\iint_{D_{2}} d F_{y} \\
F_{y 3}=\iint_{D_{3}} \sigma_{t} r^{2} \cos \theta d r d \theta \\
F_{y 4}=\iint_{D_{4}} d F_{y}
\end{array}\right.
$$

Where, $d F_{y}=E c r^{3} \sin (A+\theta) \cos \theta d r d \theta$.

$$
\begin{aligned}
F_{y}= & \sum_{i=1}^{4} F_{y i} \\
= & \frac{E c R^{4}}{4}\left\{\sin A \arcsin \left(\frac{\varepsilon_{t}}{c R}\right)-\sin A \frac{\varepsilon_{t} \sqrt{(c R)^{2}-\varepsilon_{t}{ }^{2}}}{(c R)^{2}}\right\}+ \\
& \frac{4 \sigma_{t} R^{2} c^{2}-\sigma_{t} \varepsilon_{t}{ }^{2}}{6 c^{3}} \sin A \sqrt{(c R)^{2}-\varepsilon_{t}{ }^{2}}
\end{aligned}
$$

Accordingly

$$
\begin{gathered}
\beta=\arctan \left(\frac{\bar{x}}{y}\right)=\arctan \left(\frac{F_{y}}{F}\right)= \\
=\arctan \left(\frac{\sin A}{\cos A}\right)=A
\end{gathered}
$$

\section{Calculation of inflection moment and analysis of resilience under the second condition}

\subsection{Calculation of Inflection Moment}

Under the second condition, that is meet the condition of $\arcsin \left(\varepsilon_{t} / c R\right)-A<0$, plastic deformed area of upper half section intersects $\mathrm{x}$ axis. The deformation region of upper half section includes the elastic region and elasticplastic region, so corresponding stress regions include elastic stress region and the region that fails to elastic limit. Therefore the integral domain of upper half section can be distributed into five parts, shown in Figure 4, and the dashed area represents the plastic deformed area.

The stress and bending moment correspond with the section can be expressed as the following five parts,

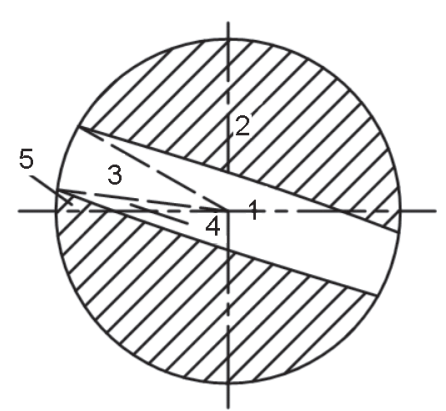

Fig. 4. The region map of the second type deformation

(1) Integral domain $D_{11}$

$$
\begin{aligned}
& 0 \leq \theta \leq \pi-A-\arcsin \left(\varepsilon_{t} / c R\right) \\
& 0 \leq r \leq \frac{\varepsilon_{t}}{c \sin (A+\theta)}
\end{aligned}
$$

The stress correspond with this domain is

$$
\sigma_{1}=\operatorname{Ecr} \sin (A+\theta)
$$

The bending stress is

$$
\begin{aligned}
& M_{1}=\iint_{D_{11}} d M= \\
& =\int_{0}^{\pi-A-\arcsin \left(\frac{\varepsilon_{t}}{c R}\right)} \int_{0}^{\frac{\varepsilon_{t}}{c \sin (A+\theta)}} E C \sin (A+\theta) \sin \theta r^{3} d r d \theta
\end{aligned}
$$

(2) Integral domain $D_{22}$

$$
\begin{aligned}
& 0 \leq \theta \leq \pi-A-\arcsin \left(\frac{\varepsilon_{t}}{c R}\right) \\
& \frac{\varepsilon_{t}}{c \sin (A+\theta)} \leq r \leq R
\end{aligned}
$$

The stress correspond with this domain is

$$
\sigma_{2}=\sigma_{t}
$$

The bending stress is

$$
\begin{aligned}
& M_{2}=\iint_{D_{22}} \sigma_{t} \sin \theta r^{2} d r d \theta= \\
& =\sigma_{t} \int_{0}^{\pi-A-\arcsin \left(\frac{\varepsilon_{t}}{c R}\right)} \sin \theta d \theta \int_{\frac{\varepsilon_{t}}{c \sin (A+\theta)}}^{R} r^{2} d r
\end{aligned}
$$

(3) Integral domain $D_{33}$

$\pi-A-\arcsin \left(\frac{\varepsilon_{t}}{c R}\right) \leq \theta \leq \pi-A+\arcsin \left(\frac{\varepsilon_{t}}{c R}\right)$ $0 \leq r \leq R$

The stress correspond with this domain is

$$
\sigma_{3}=\operatorname{Ecr} \sin (A+\theta)
$$

The bending stress is 


$$
\begin{aligned}
& M_{3}=\iint_{D_{33}} d M= \\
& =\int_{\pi-A-\arcsin \left(\frac{\varepsilon_{t}}{c R}\right)}^{\pi-A+\arcsin \left(\frac{\varepsilon_{t}}{2 R}\right)} \int_{0}^{R} E C \sin (A+\theta) r^{3} \sin \theta d r d \theta \\
& =E C \int_{\pi-A-\arcsin \left(\frac{\varepsilon_{t}}{c R}\right)}^{\pi-A+\arcsin \left(\frac{\varepsilon_{t}}{c R}\right)} \sin (A+\theta) \sin \theta d \theta \int_{0}^{R} r^{3} d r
\end{aligned}
$$

(4) Integral domain $D_{44}$

$$
\begin{aligned}
& \pi-A+\arcsin \left(\frac{\varepsilon_{t}}{c R}\right) \leq \theta \leq \pi \\
& 0 \leq r \leq \frac{\varepsilon_{t}}{c \sin (A+\theta)}
\end{aligned}
$$

The stress correspond with this domain is

$$
\sigma_{4}=\operatorname{Ecr} \sin (A+\theta)
$$

The bending stress is

$$
\begin{aligned}
& M_{4}=\iint_{D_{44}} d M= \\
& =\int_{\pi-A+\arcsin \left(\frac{\varepsilon_{t}}{c R}\right)}^{\pi} \int_{0}^{\frac{\varepsilon_{t}}{c \sin (A+\theta)}} E C \sin (A+\theta) r^{3} \sin \theta d r d \theta \\
& =E C \int_{\pi-A+\arcsin \left(\frac{\varepsilon_{t}}{c R}\right)}^{\pi} \sin (A+\theta) \sin \theta d \theta \int_{0}^{\frac{\varepsilon_{t}}{c \sin (A+\theta)}} r^{3} d r
\end{aligned}
$$

(5) Integral domain $D_{55}$

$$
\begin{gathered}
\pi-A+\arcsin \left(\frac{\varepsilon_{t}}{c R}\right) \leq \theta \leq \pi \\
\frac{\varepsilon_{t}}{c \sin (A+\theta)} \leq r \leq R
\end{gathered}
$$

The stress correspond with this domain is

$$
\sigma_{5}=-\sigma_{t}
$$

The bending stress is

$$
\begin{aligned}
M_{5} & =-\iint_{D_{55}} \sigma_{t} \sin \theta r^{2} d r d \theta \\
& =-\int_{\pi-A+\arcsin \left(\frac{\varepsilon_{t}}{c R}\right)}^{\pi} \int_{\frac{\varepsilon_{t}}{c \sin (A+\theta)}}^{R} \sigma_{t} \sin \theta r^{2} d r d \theta \\
& =-\sigma_{t} \int_{\pi-A+\arcsin \left(\frac{\varepsilon_{t}}{c R}\right)}^{\pi} \sin \theta d \theta \int_{\frac{\varepsilon_{t}}{c \sin (A+\theta)}}^{R} r^{2} d r
\end{aligned}
$$

Total bending moment of the circular section is

$$
\begin{aligned}
M= & 2 \sum_{i=1}^{5} M_{i}= \\
= & \frac{6 \sigma_{t} \varepsilon_{t}{ }^{2}+8 \sigma_{t} R^{2} c^{2}-3 E R^{2} c^{2}}{6 c^{3}} \cos A \sqrt{(c R)^{2}-\varepsilon_{t}{ }^{2}}+ \\
& +\frac{2 \sigma_{t} \varepsilon_{t}{ }^{3}}{3 c^{3}}\left\{\frac{1}{\sin A}-\sin A\left(\frac{c R}{\varepsilon_{t}}\right)^{2}-2 \cos A \cot A\right\}+ \\
& +\frac{E c R^{4}}{2} \cos A \arcsin \left(\frac{\varepsilon_{t}}{c R}\right)
\end{aligned}
$$

\subsection{Analysis of Resilience}

Corresponding to the five integral domains divided by the upper half section under the status of $\arcsin \left(\varepsilon_{t} / c R\right)-A<0, F_{x}$ consists of the five parts

$$
\left\{\begin{array}{l}
F_{x 1}=\iint_{D_{11}} d F_{x} \\
F_{x 2}=\iint_{D_{22}} \sigma_{t} r^{2} \sin \theta d r d \theta \\
F_{x 3}=\iint_{D_{33}} d F_{x} \\
F_{x 4}=\iint_{D_{44}} d F_{x} \\
F_{x 5}=-\iint_{D_{55}} \sigma_{t} r^{2} \sin \theta d r d \theta
\end{array}\right.
$$

Where $d F_{x}=E c r^{3} \sin (A+\theta) \sin \theta d r d \theta$

Correspondingly

$F_{x}=\sum_{i=1}^{5} F_{x i}=\frac{5 \sigma_{t} R^{2} c^{2}+6 \sigma_{t} \varepsilon_{t}^{2}}{12 c^{3}} \cos A \sqrt{(c R)^{2}-\varepsilon_{t}^{2}}+$ $+\frac{E c R^{4}}{4} \cos A \cdot \arcsin \left(\frac{\varepsilon_{t}}{c R}\right)+$

$+\frac{\sigma_{t} \varepsilon_{t}{ }^{3}}{3 c^{3}}\left\{\frac{1}{\sin A}-2 \cos A \cot A-\sin A \cdot \frac{(c R)^{2}}{\varepsilon_{t}{ }^{2}}\right\}$

Similarly, $F_{y}$ is made up of the following five parts

$$
\left\{\begin{array}{l}
F_{y 1}=\iint_{D_{11}} d F_{y} \\
F_{y 2}=\iint_{D_{22}} \sigma_{t} r^{2} \cos \theta d r d \theta \\
F_{y 3}=\iint_{D_{33}} d F_{y} \\
F_{y 4}=\iint_{D_{44}} d F_{y} \\
F_{y 5}=-\iint_{D_{55}} \sigma_{t} r^{2} \cos \theta d r d \theta
\end{array}\right.
$$

Therefore

$$
\begin{aligned}
& F_{y}=\sum_{i=1}^{5} F_{y i}= \\
& =\frac{5 \sigma_{t} R^{2} c^{2}+6 \sigma_{t} \varepsilon_{t}{ }^{2}}{12 c^{3}} \sin A \sqrt{(c R)^{2}-\varepsilon_{t}{ }^{2}}+ \\
& +\frac{E c R^{4}}{4} \sin A \cdot \arcsin \left(\frac{\varepsilon_{t}}{c R}\right)+ \\
& +\frac{\sigma_{t} \varepsilon_{t}^{3}}{3 c^{3}}\left\{\cos A \cdot \frac{(c R)^{2}}{\varepsilon_{t}{ }^{2}}-\frac{\cos A}{\sin ^{2} A}-2 \sin A \cot A\right\} \\
& \qquad \beta=\arctan \left(\frac{x}{\bar{x}}\right)=\arctan \left(\frac{F_{y}}{F_{x}}\right)
\end{aligned}
$$




\section{Straightening roller system configu- ration design of three-roller equal curvature}

The requirements for roller system by reasonable straightening process adopting parallel roll system are unify the residual error of bar to achieve equal curvature, during straightening the bar does not revolve on its axis to ensure two mutually perpendicular straightening plane do not change and truly realize two dimensional straightening. The structure of roller system presented in this paper is shown in Figure5. Large deformation is exerted on the bar to unify the residual error of bar to achieve equal curvature and the bar does not rotate during the process of straightening. The straightening effect is achieved by the repeated deformation in the two straightening planes and the bending state belongs to the second strain state.

Take the bar with elastic module $E=2.06 \times 1011 \mathrm{~Pa}$, yield stress $\sigma_{t}=4 \times 108 \mathrm{~Pa}$ and radius $\mathrm{R}=6 \mathrm{~mm}$ for example, the bending moment can be obtained, shown in Figure 6, when inflection curvature ratio is 3,4 and 5 respectively under the condition of original curvature ratio is 3 . The included angle between resilience plane and inflection plane varies with the included angle between original bending plane and inflection plane, shown in Fig. 7.

It is shown in Figure 6 that under the definite original curvature ratio, inflection-bending moment increases with the increase of inflection curvature and decreases with the increase of included angle between original bending plane and inflection plane. When original bending plane and inflection plane are in the same plane, the inflection bending moment reaches its maximum. When the included angle between original plane and inflection plane is 900 (namely they are perpendicular), the inflection moment reaches its minimum under the same conditions.

It is shown in Figure 7 that during the process of inflection straightening, under the definite original curvature ratio, the included angle between resilience plane and inflection plane decreases with the increase of inflection curvature ratio and increases with the increase of included angle between original bending plane and inflection plane. Namely in the definite original bending degree, the more the reverse bending degree, the more the resilience plane is prone to reverse bending plane; the more the included angle between original bending plane and inflection plane, the more the included angle between resilience plane and inflection plane.

The included angle between resilience plane and inflection plane is far smaller than the included angle between original bending plane and reverse bending plane. This phenomena

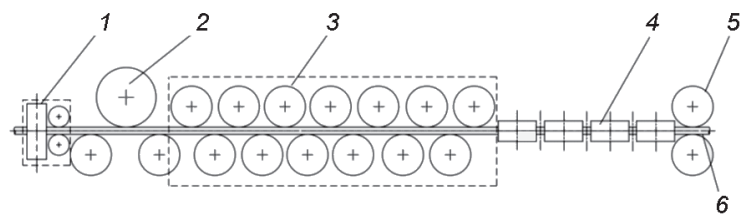

Fig. 5. Sketch map of straightening roller system; 1 - leading equipment, 2 - three-roller straightening system, 3 - horizontal straightening system, 4 - vertical straightening system, 5 - draw off roll, 6 - bar

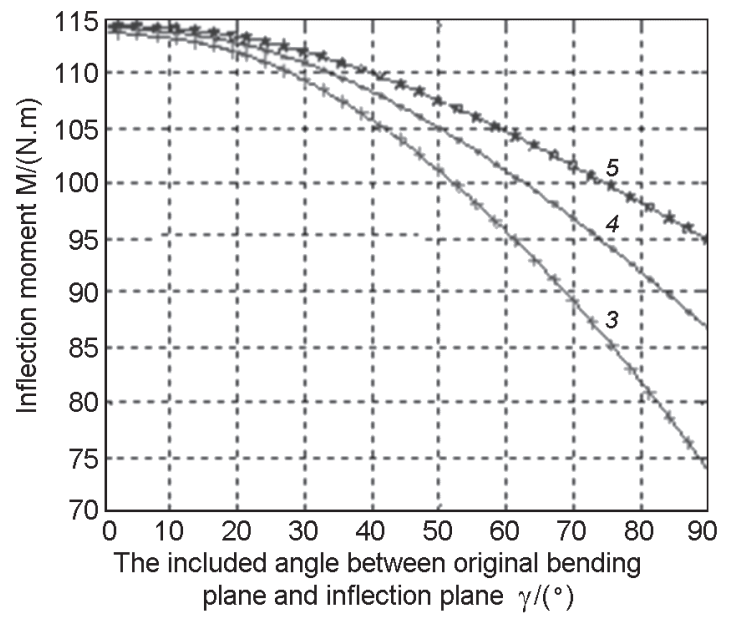

Fig. 6. The relationship of recurvate curvature ratio and bending moment

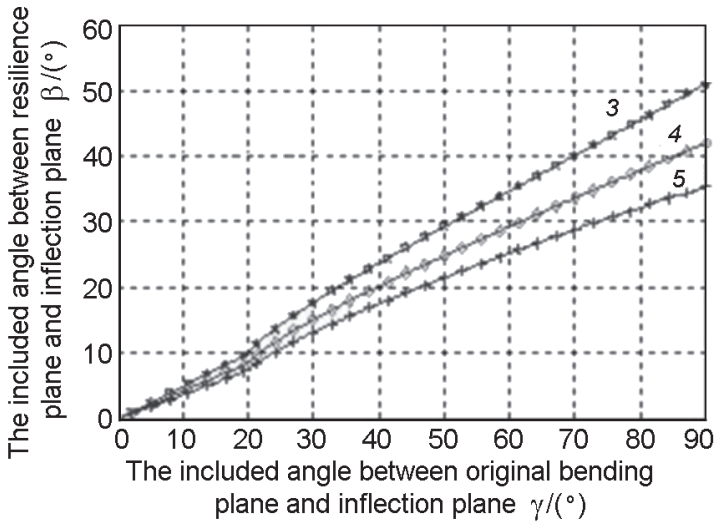

Fig. 7. The relationship of recurvate curvature ratio and resilience

shows that rebound plane turn around neutral axis to inflection plane during the resilience process of bar. So it can be deduced that during the repeated inflection straightening of bar in a fixed plane, the bending of infinitesimal section of the bar in each plane tend toward the same plane, that is inflection plane. For roll straighter, the inflection plane is immovable and the bending of each direction tends toward the same plane.

Take the bar with original curvature ratio $C_{0}=2.0, C_{0}=2.4, C_{0}=2.8$ and $C_{0}=3.0$ for example and assume the initial angle a between 
Table 1. Relationship of inflection frequency and rebound

\begin{tabular}{|c|c|c|c|c|}
\hline \multirow{2}{*}{$n$} & \multicolumn{4}{|c|}{$C_{0}$} \\
\cline { 2 - 5 } & 2.00 & 2.40 & 2.80 & 3.00 \\
\cline { 2 - 5 } & \multicolumn{4}{|c|}{$\beta$} \\
\hline 1 & 16.55 & 17.86 & 18.94 & 19.41 \\
\hline 2 & 8.76 & 8.92 & 9.02 & 9.06 \\
\hline 3 & 4.26 & 4.34 & 4.39 & 4.42 \\
\hline 4 & 2.56 & 2.59 & 2.61 & 2.63 \\
\hline 5 & 1.72 & 1.74 & 1.75 & 1.76 \\
\hline 6 & 1.25 & 1.26 & 1.26 & 1.27 \\
\hline 7 & 0.95 & 0.96 & 0.96 & 0.96 \\
\hline
\end{tabular}

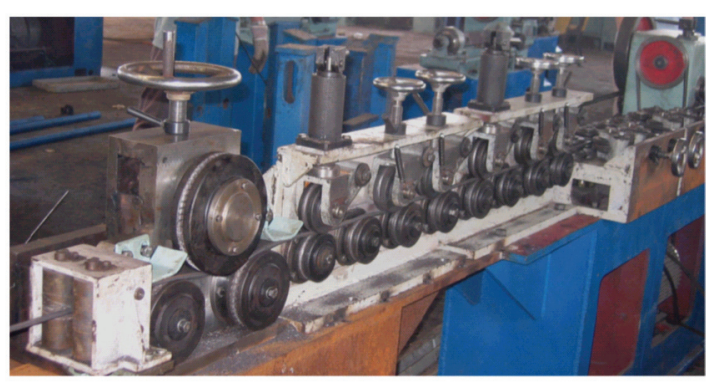

Fig.8. The implementation of straightening scheme

original bending plane and inflection plane is 60 degree, the included angle $B$ between resilience plane and inflection plane after every infection is listed in Table 1, where $\mathrm{n}$ is inflection times.

It is displayed in Table 1 that the included angle between resilience plane and inflection plane decreases rapidly for any bar of original curvature ratio during the inflection process of 7 times, the influence that original curvature on resilience is small, the included angle between resilience plane and inflection plane decreases to a very small value after the inflection process of 7 times. This indicates that the bending plane has unified to inflection plane basically after the inflection process of 7 times.

Therefore, it can be deduced that by using slab edge combination roller system to straighten bars and adopting appropriate roll numbers and inflection curvature, in two straightening planes which is perpendicular to one another, whatever the original bending degree and bending status are, the goal that bars can bend in arbitrary direction can be achieved completely as long as the bar does not rotate around its own axis during straightening course.

Based on above research and analysis, taking bars with $12 \mathrm{~mm}$ diameter as objects, we conducted experiments in the straightening mechanism shown in Figure 8. The results show that after bars passing through threeroller system, the circumferential rotation phenomenon has been eliminated. The implementation of two-dimensional straightening in perpendicular direction of bars at any axial cross section has been guaranteed and thus the straightening precision can be improved.

\section{Conclusions}

In view of calculation of inflection moment and confirmation of resilience plane at any direction bending of bars for slab edge combination roll system, reasonable mathematical model is established in this paper to deduce calculation expressions of inflection moment while original bending plane is at angle to inflection plane and ascertain corresponding resilience orientation. The significant conclusions that resilience plane turn around bar's axis to inflection plane and the turning angle increases with the increase of inflection curvature ratio are drawn. Thus the goal that bar can bend in any direction can be achieved by adopting appropriate roll numbers and inflection curvature.

\section{Acknowledgements}

This work was financially supported by Natural Science Foundation of Steel and Iron Foundation of Hebei Province of China (grant no. E2014203118) and Hebei province Science Technology Research and Development Program (No.12215604D)

\section{References}

1. J.C.Wang, , Iron and Steel, 41, 52, 2006.

2. H.G.Wang, X.J Liu, H.S. Liu, Adv. Mater. Res., 189-193, 2387, 2011.

3. R. Hamada, M. Asakawa, M. Nagahiral, M. Amari, , Wire J. Intern., 41, 81, 2008.

4. M.L.MartinezPerez, C.R. Borlado, F. J. Mompean, et.al., Acta Mater., 53, 4415,.2005.

5. Q.D.zhang, S.Zhou, J.C. Yin, Chin. J. Eng., 37, $789,2015$.

6. A.Pernía, F.J.Martínez-De-Pisón, J. Ordieres, Iron. Steel., 37, 119, 2010.

7. N.K. Das Talukder, A.N.Singh, J. Eng,. Indust.. $113,224,1991$.

8. R.Hamada, M. Asakawa, S. Irisawa, et.al., J. Iron Steel Inst. Japan, 95, 780, 2009.

9. K. Kazeem, Adewole, Global J.Res. Eng.-E:Civil Struct. Eng. 12, 1, 2012.

10. R.Kaiser, T. Hatzenbichler, B. Buchmayr, T. Antretter, Mater. Scie. Forum, 768-769, 456, 2014,

11. H.Lu, H. Ling, J. Leopold, X.Zhang, C.Q. Guo, Scie. China, Series E: Techn. Scie., 52, 1866, 2009.

12. W. Guericke, Steel Res. Intern., 80, 281, 2009. 